\title{
El ensayo de Sergio Pitol, un cuaderno de bitácora*
}

\author{
María del Pilar Vila**
}

\begin{abstract}
Resumen
La obra de Sergio Pitol muestra los recorridos que realiza el mexicano a través de la literatura para encontrar en ella el sostén de su narrativa ficcional y ensayística. Cada viaje físico y mental adquiere la dimensión de un símbolo en la medida que constituye un camino para acercar autores, renovar las lecturas y, sobre todo, encontrar puntos de conexión con su propia obra. Viajar y escribir son modos de engarzar experiencia y escritura y reactualizar procesos de crítica y de interpretación de los textos de la cultura.
\end{abstract}

Palabras clave: Ensayo, Sergio Pitol, viaje, lectura.

\section{Sergio Pitol's essay, a logbook}

\begin{abstract}
The work of Sergio Pitol shows the Mexican's explorations of literature to find the support to his fiction and essays. Each physical and mental trip gains the dimension of a symbol to the extent that it is a way to bring together authors, renew readings and, above all, find points of connection within his own work. Traveling and writing are ways of linking experience and writing and updating processes of criticism and interpretation of cultural texts.
\end{abstract}

Keywords: essay, Sergio Pitol, travel, reading.

Recibido: 11-08-2012

Aceptado: 27-12-2012

* Este trabajo surge del proyecto Trayectorias del ensayo literario mexicano a través de la generación del medio siglo. Lecturas, traducciones, tradiciones, inscrito en el marco en el marco de Programa Nacional de Incentivos a la Investigación.

** Argentina. Doctora en Letras. Universidad Nacional del Comahue, Argentina. mpilarvila@gmail. com 
Pertinaz viajero, Sergio Pitol (1933) disemina las huellas de sus andanzas geográficas y de sus recorridos literarios a lo largo de su prolífica obra. Los desplazamientos físicos repercuten en los mentales entrelazando viajes y lecturas porque para él, cada traslado es una nueva ocasión para redescubrir el mundo y gozar con ello. A la manera del flâneur se detiene durante los paseos por ciudades emblemáticas, en casas de escritores o en bibliotecas, haciendo de cada visita un sitio literario y tomando conciencia de que "Al recorrer el interior [de la casa] no pude pensar sino que estaba husmeando en la casa de una tribu" (La casa de la tribu:11) porque, además, la casa de Tolstoi -de ella se trata-le suministra "más sobre los novelistas rusos del siglo XIX que cualquier tratado histórico o literario." (ibid). La afirmación de acceder a la casa de una tribu implica, además, su ingreso en un ámbito del que quiere ser partícipe y que encontrará albergue en su narrativa ficcional y ensayística. Por otra parte, estar en esos lugares literarios, como también en cada nuevo destino adonde su papel de diplomático lo llevara, tienen la dimensión de un símbolo. Es una forma de acercar autores, de renovar las lecturas pero, sobre todo, lo lleva a encontrar puntos de conexión con su propia obra puesto que la lee y la piensa en cada uno de esos encuentros.

Las embajadas y los países donde estuve en ellas fueron ubérrimas en experiencias. Mis libros, aun ahora, se alimentan de ellas. Si de algo puedo estar seguro es de que la literatura y sólo la literatura ha sido el hilo que ha dado unidad a mi vida. Pienso ahora a mis setenta años que he vivido para leer; como una derivación de ese ejercicio permanente llegué a ser escritor. (El mago de Viena 228)

Viaje y literatura son modos de engarzar experiencia y escritura y, al mismo tiempo, son una forma de reactualizar procesos de crítica y de interpretar de los textos de la cultura. (Weinberg) Pitol reflexiona ante el impacto que le producen los hogares de los escritores buscando dialogar con el lector y consigo mismo. Por otra parte, la ciudad como lugar simbólico ofrece una nueva sensibilidad, al percibir en ella una atmósfera propicia para el diálogo y la discusión.

Marcel Proust sostiene que el placer que uno encuentra en una ciudad $^{1}$ no radica únicamente en la contemplación de edificios notables

1 Alude a Beaune, Francia. 
que lo hacen sentir próximo a la obra, por ejemplo, de Racine o de SaintSimon, sino que lo valioso está en el hecho de que las ciudades "contienen todas las bellas modalidades abolidas de la lengua y atesoran el recuerdo de usos o maneras de sentir que ya no existen, huellas persistentes del pasado al que nada del presente se parece y en donde sólo el tiempo, al pasar sobre ellas, ha podido embellecer su color."2 Sin dudas, el ámbito ciudadano ejerce una fuerte atracción en quien puede hallar rastros del pasado y renovarlos a partir de su experiencia y obviar así, el hecho de que esa ciudad evocada o soñada sufrió las modificaciones del tiempo. Tanto la nostalgia como la memoria constituyen un par fundamental para darle cuerpo al encuentro del escritor -que es al mismo tiempo viajero, cronista y ensayista-con las ciudades literarias. Deposita, de esta manera, en esos ámbitos ciudadanos toda la capacidad de la escritura, en especial la del ensayo porque éste, más que cualquier otro género, nos constriñe a repensar sus vínculos con la ficción, la verdad y lo agónico (Glaudes; 1999:31).

La herencia recibida de aquel deambular por cafés, teatros y librerías en un México de mediados del siglo XX que asomaba a la modernidad, caracteriza su escritura y su relación con la ciudad. De esos paseos se nutre también la literatura de otros compañeros generacionales, como Salvador Elizondo quien llevó el erotismo al plano filosófico e hizo del lenguaje un tema central para su ensayismo. O la de Juan García Ponce, capaz de reunir los deseos con las fantasías para expresar que la literatura, en tanto pasión, es un espacio autónomo que se maneja con sus propias reglas. Desde ese lugar, García Ponce reflexiona acerca del sentido de la vida, del valor de la cultura, del significado de ciertos nombres que, con su sola mención, hacen "posible que la cultura [aparezca] viva ante nosotros". (158). El gran mérito de estos escritores radicó en la producción de obras centrales para la literatura mexicana y en el hecho de que fueron notables críticos de distintos campos artísticos e incursionaron, además en el ámbito de la traducción tal como lo certifican los trabajos de José Emilio Pacheco, Inés Arredondo o Humberto Batis, además de los mencionados con anterioridad.

Sergio Pitol nutre su escritura de la atmósfera urbana a partir de su rica experiencia como viajero y por la evocación de un tiempo caracterizado

2 En (2005) Sobre la lectura, Buenos Aires: Libros del Zorzal. Traducción de Pedro Ubertone: 64-65. 
por una "intensa excentricidad donde amigos de distintas edades, nacionalidades y profesiones convivíamos con absoluta naturalidad" y cuya particularidad radicaba en "el fervor por el diálogo, siempre y cuando fuera divertido e inteligente, la capacidad para la parodia, la falta de respeto a los valores prefabricados, a las glorias postizas, a la petulancia y, sobre todo, a la autocomplacencia." ${ }^{3}$

La evocación de un tiempo de creación y de audacia se entrelaza con la revisión de lecturas y el redescubrimiento de autores, lo que significará incursionar por caminos de renovación y mostrar el valor de la interacción de diálogos. Las frecuentes alusiones a quienes imagina compartiendo los recorridos, junto con la presencia viva de la ciudad se convertirán en un motivo recurrente. El paseante deambula por lugares que condensan historias literarias y, en un sentido más amplio, dibuja campos culturales donde están presentes sitios emblemáticos y los de libros que va recordando como un modo de dialogar con la tradición, porque "[1]o natural es que con el tiempo cada escritor reconozca pertenecer a una determinada familia literaria. Una vez establecido el parentesco es difícil escapar de él; lo sería si fuera por cuestiones ideológicas o religiosas, pero no estéticas." (El mago de Viena 26)

Cada viaje, entonces, es un encuentro con la literatura: es cartografiar "la geografía del intelecto"4 para reanudar conversaciones con José Emilio Pacheco y Carlos Monsiváis (Una autobiografía soterrada 18) es encontrar la "Forma" (19), la poesía cubana (22) o la pintura, como señala en El viaje (84-85). Es reconfirmar lo que significaron Juan Rulfo, Augusto Monterroso o Jorge Luis Borges para la literatura latinoamericana. Llegar a Moscú o a Varsovia es redescubrir una literatura que lo ayuda a fortalecer sus ideas acerca del sentido del viaje, del peso de la ciudad y del valor de las diferentes culturas. Cada contacto le permite articular la literatura con otras expresiones artísticas del mismo modo que cada lectura lo lleva a ampliar y construir su propio canon lector: "Me sentía soñado: un apóstol de la cultura, de la apertura al mundo de mi país, y al mismo tiempo vivía experiencias formidables, tratar personajes interesantes, ampliar conocimientos, todo eso" (El mago de Viena 62)

3 En "Soñar la realidad", publicado en pdf por el Instituto de Investigaciones Lingüístico-literarias. Universidad Veracruzana: 7. Tomado de Internet el 12 de marzo de 2010. Fue editado con el título (2006) Soñar la realidad. Una antología personal. Madrid: Mondadori.

4 Concepto acuñado por Carlos Monsiváis. 
Para Pitol, como para muchos de sus compañeros de ruta, la literatura tiene sólidos vínculos con la pintura, la música, la filosofía, la política. Las referencias a estos campos del saber están en todos sus libros y son los disparadores para que despliegue su condición de agudo crítico y de profundo conocedor de los más variados temas, cuestiones que en ocasiones lo llevan a pensarse como quien es capaz de leer desde un lugar distinto y así poder rearmar guías de lecturas. Acertadamente, Jorge Volpi señala: "¡Viajar y escribir! Actividades ambas marcadas por el azar; el viajero, el escritor, sólo tendrán certeza de la partida. Ninguno de ellos sabrá a ciencia cierta lo que ocurrirá en el trayecto, menos aun lo que le deparará el destino al regresar a su Ítaca personal" (103). Cabría agregar que ese regreso se puebla de imágenes que reenvían a su propia obra. Por eso para él "[e]scribir se volvió una obsesión; creo que la agobiante actividad social a la que me veía obligado por motivos protocolarios de alguna manera nutrió de anécdotas, episodios, gestos, frases y tics las novelas que allí escribí" (Todo está en todas las cosas: 11).

Si bien Pitol es un escritor "sólidamente mexicano", su fascinación por el mundo europeo oriental está a la vista ya que las lecturas de autores de esta región atraviesan sus libros. Se puede sostener que para Pitol la literatura es un palimpsesto que impulsa al lector a "develar la superposición de escrituras que la componen." Encontrarse con los temas que ya habían sido diseñados por otras literaturas es uno de los tópicos recurrentes porque postula la producción y reproducción a partir de otros textos. Como en el juego de la palmada, las escrituras ajenas tocan las propias y permiten que esas resonancias se enraícen en su escritura. ${ }^{6}$ Es, además, el lugar donde se revisan conceptos teóricos y se señalan esos débiles límites que la teoría ha impuesto al construir una taxonomía genérica, lo que lo lleva a posicionarse como lector y como crítico. Estas constantes alusiones a aspectos teóricos generan la inclusión de nombres y comentarios de ese campo, como por ejemplo Susan Sontag o M. Bajtin. Lo que sí queda explicitado es su descreimiento de las clasificaciones, al tiempo que se declara incapaz de escribir un ensayo -"lo que en mí sería grotesco"- torciendo esa intención hacia el armado de una "crónica literaria en clave menor" (10), afirmación por cierto contradictoria con lo

5 Esta afirmación la hace Luis Alberto Quevedo refiriéndose a la ciudad. Cf. "Prólogo" de García Canclini, Néstor. (1997) Imaginarios urbanos. Buenos Aires, Eudeba: 11-15.

6 R. Barthes llama a esta operación la main chaude. Cfr. (2004) Roland Barthes por Roland Barthes. Barcelona: Paidós. Traducción de Julieta Sucre: 70. 
que realiza en varios de sus libros. Estas cuestiones no son, por cierto, privativas de la obra de Pitol. En los ensayos de varios de sus compañeros de generación están presentes reflexiones acerca de los aspectos genéricos y las consecuencias de mostrar la hibridez, por caso, del ensayo. La imposibilidad de encuadrar algunos trabajos en un género hizo que éstos no encontraran espacio en editoriales. Salvador Elizondo hace referencia a estas dificultades en la "Introducción" de Contexto. ${ }^{7}$ Participa de estas inquietudes Juan García Ponce, tal como lo señala Ángel Rama en "El arte intimista de García Ponce". ${ }^{8}$ Cada ensayo pitoliano es una 'cápsula' que contiene su historia de lecturas, sus viajes, su vínculo con la literatura y con las ciudades. La afirmación de que sus textos "son un espejo cierto de mis movimientos, una crónica del corazón, un registro de mis lecturas y el catálogo de mis curiosidades de entonces. Son los cuadernos de bitácora de una época muy agitada." (El mago de Viena 91), lo colocan en el lugar del analista de su propia obra. Cada libro es, entonces, un conjunto de voces que se amplifica recogiendo tradiciones y abriéndose a la novedad o a la renovación. Es precisamente esta intención la que lo lleva a entrecruzar su escritura con la de autores rusos, por ejemplo.

En La casa de la tribu, Pitol dedica un notable espacio al análisis de la obra de Gogol, el que se sostiene por sus opiniones de lector pero también por reflexiones amparadas por lecturas críticas y teóricas. Aporta datos provenientes de la vida privada de Gogol, de la trayectoria literaria y referencias a las líneas imperantes en la narrativa rusa contemporáneas al autor de Las almas muertas. Alude, además, a la significación del viaje en el contexto de la novela porque considera que éste "se convierte casi en una necesidad estructural de la novela y el viajero es una pieza necesaria para el desarrollo de la trama" (33).

La posición del ensayista queda a la vista: lo que se cuenta se imbrica con su pensamiento en lo referido al valor otorgado al viaje, empleando el legado de Gogol para expresar su idea de la literatura y transmitir al lector su experiencia. Cómo, entonces, no leer este libro como un singular ensayo, sobre todo teniendo en cuenta las afirmaciones de C. de Obaldía referidas a este género: "as with any other genre, the essay's potential contribution to literatura is dependent upon the arbitrary criteria of 
value that determine cannons" (4). Esta idea habilita al lector a encuadrar algunos trabajos pitolianos en la categoría de crónica o de trabajo de crítica literaria pero sin dudas puede reconocer varias particularidades del ensayo. Se reconfirma aquello de que el género se define por la manera de representación (Ricoeur 31), especialmente al pensar el ensayo como el género que alberga en sí mismo la tensión existente cuando se trata de fijar fronteras entre lo ficticio y la verdad. Esta pérdida de límites entre ficción y ensayo -obsesiones recurrentes en la obra pitoliana- muestra que está en juego el concepto de literatura, ese saber que construye con diferentes culturas, con parentescos de otras literaturas, con citas y con voces que se espejarán en su propia obra.

Los ensayos de Pitol, como una verdadera casa de la tribu o como un 'álbum de familia', se pueblan de referencias a autores que habitan en su obra y en cada lectura o relectura renacen las voces de B. Pilniak, A. Chéjov, M. Tsvietáieva, J. Borges, A. Reyes. Cada uno de ellos le provee distintos modos de relacionarse con la literatura y, al mismo tiempo, las referencias a estos autores operan como una manera de pensar su propia escritura. En un sentido más amplio son el espacio donde despliega sus ideas acerca del proceso creador que lo impulsa, aunque no deja de lado aspectos que remiten a teorías literarias, otorgando a sus afirmaciones un soporte teórico. De este modo, Pitol ofrece al lector distintos puntos de ingreso a su obra, conduciéndolo a una escritura que fusiona ensayo, crítica, teoría y ficción. Definir el cuento, abandonar modelos, reencontrarse con escritores, trazar un nuevo territorio de la literatura son algunos de los ejes abordados y dan cuenta de sus obsesiones, nacidas básicamente de su pasión por la lectura. Escenas infantiles o juveniles enmarcan ese interés de cuya significación deja referencias en varios libros:

Pasé la niñez en un ingenio azucarero, en Potrero, Veracruz, lugar tan insalubre como con toda seguridad lo habrán sido en la misma época las fincas de Nueva Guinea, del Alto Volta o de la Amazonia. [...] Mi único placer provenía de la lectura. De grado y por fuerza me convertí en lector de tiempo completo. [...] Leí todo lo que cayó en mis manos. (El arte de la fuga, 110).

Si es cierto que las pulsiones de la niñez nos acompañarán hasta el momento de morir, también lo es que el escritor deberá mantenerlas a raya, evitar que se conviertan en un candado 
para que la escritura no se transforme en cárcel, sino en reserva de libertades. (Pasión por la trama, 27)

R. Barthes sostiene que preguntarse sobre la lectura, esto es sobre la significación del propio acto, es un modo de entender todas las lecturas y de "reclamar una teoría de la lectura" (35), para preguntarse luego si la lectura no sería algo así como pulsión infantil. De ese desborde vital que siente Pitol por la lectura nace su relación con la literatura a la que no entiende si no es entrelazada con el acto lector. Lectura y escritura son los hilos que traman su obra. La reiteración de estas operaciones modula el conjunto del corpus narrativo. No es posible reflexionar sobre la tradición literaria, o sobre la significación de la obra de O. Paz, o de A. Reyes, o de J. L. Borges, si no es a partir del peso de "la auténtica lectura, la relectura" (El mago de Viena, 24). Sólo así piensa que puede escribir; de ese acto hedonista surgen sus textos ficcionales y sus ensayos y es precisamente esa ligazón la que lo guía a desdibujar límites genéricos.

Toda su obra evidencia un profundo conocimiento de diversas literaturas y teorías literarias y para hacerlo reorganiza una serie de datos, referencias, historias, ficciones, diario privado y diálogos, yuxtaposición que le permite plantear o presentar novedades, lo que significa un aspecto central para sostener su idea de la literatura. Todo cabe en ella y la fusión de aspectos contradictorios es lo que da paso a la magia de la ficción y a la riqueza de la reunión de opuestos como un modo de ligar tiempos y espacios. En la obra ensayística de Pitol la ficción ocupa un lugar importante, tal como se observa en El viaje; la preparación de Domar a la divina garza $9^{9}$ forma parte de ese libro y su autor destaca como punto inicial la lectura y la certeza de que debe revisar la literatura. Ante el interrogante de cómo ésta ingresa en el libro, la respuesta es múltiple ya que uno de los primeros modos en que lo hace es ligando lecturas y autores. También impone ciertos caminos de lectura que remiten a los linajes literarios, cuestión que le permite pensarse como escritor y elegir la tradición en la que se inscribirá. Los precursores se diseminan a lo largo de casi toda la obra pitoliana y son releídos apelando al ensayo:

Leí todo Ripellino, sus libros sobre literatura rusa, la antología checa, sus ensayos todos podrían estar comprendidos en

9 Dedicado a Juan García Ponce, destacado ensayista y compañero de generación. Cfr. pág. 159. 
el título de uno de sus libros extraordinarios. Ensayos en forma de baladas; a los formalistas rusos, comenzando por Shklovski [...]; al Bajtin de La cultura popular [...], que tuvo amplia participación en las novelas que escribí en Praga, y masivamente a Chéjov y Gógol, leídos y releídos a toda hora y en cualquier lugar. (El viaje 19-20)

Es, entonces, en este género donde quedan a la vista niveles de subjetividad muy altos y donde el ensayista emerge como un policéfalo de la argumentación (Glaudes 124).

El proceso de la escritura está presente en sus textos ficcionales y también en los ensayos y lo hace apelando al juego casi de cajas chinas, un texto incluye a otro y ese da paso a uno nuevo. Pitol sobreimprime $\mathrm{su}$ obra en la de otros escritores porque se piensa como "una sombra de la sombra de alguien"10, sintiéndose próximo a algunos excéntricos escritores a los que va incorporando en el gran álbum de familia que va construyendo en el interior de su obra. A partir de esta operación, se puede visualizar que, como afirma, la literatura será

[c]omplejo mecanismo de relojería donde la extrema generosidad convive y participa con crímenes inmundos, donde los mejores ideales que ha concebido y realizado el ser humano no logran apartarlo de sus infinitas torpezas, sus mezquindades y sus perennes demostraciones de desamor a la vida, al mundo, a sí mismo; creará con su pluma personajes y situaciones admirables. (El viaje 9-10)

Las reflexiones sobre la literatura, la teoría y la crítica se pueden observar no sólo en los ensayos que integran, por ejemplo, El arte de la fuga o El viaje o La casa de la tribu, sino también en la obra ficcional y en los prólogos o notas introductorias a las traducciones, por caso, de Henry James $^{11}$ o de la selección de cuentos polacos, o de relatos y novela de Boris Pilniak. Ambas discursividades -novela y ensayo- son el espacio donde se disemina su obsesión creadora: lectura y escritura se reúnen explicando el lugar que ocupan las referencias a autores e inclusive las

10 Cfr. Tsvietáieva, Marina (2009), Mi Pushkin, Barcelona, Acantilado. Traducción de Selma Ancira. En El viaje alude a esta traducción y destaca el trabajo de Ancira. Cfr. pág. 65.

11 James, Henry (1998). Los papeles de Aspern. Caracas: Monte Ávila Editores. Traducción y prólogo de Sergio Pitol. 
relaciones entre éstos y las editoriales. De modo que la idea de literatura cubre todos los campos que la implican: producción y mercado. Conviene recordar que los miembros de la Generación del Medio Siglo tuvieron una activa participación en tareas de difusión cultural, lo que significó una clara necesidad de relacionarse con el público y con el mercado. De estas operaciones hay registros en la ensayística pitoliana puesto que con frecuencia alude al trato que tenía con escritores y editores (Una autobiografía autorizada 57; El arte de la fuga 14; El mago de Viena 91).

En el prólogo a Antología del cuento polaco, Pitol se reencuentra con Varsovia precisamente a partir de su voluntad por conocer de modo directo la literatura polaca. "Leía todo lo que podía conseguir -bastante poco por cierto- en traducciones para mí comprensibles" (5) y de la tarea que se impone para traducir ese "[m]undo donde un pasado casi legendario aflora aún en potentes chispazos de irracionalidad, de poesía, de maldad o pureza" (ibid). Emprender esta actividad es lo que U. Wilamowitz-Moellendorf condensó con precisión: "Sólo el conocimiento de otra lengua portadora de otro modo de pensar hace posible la correcta comprensión de la propia lengua"12. La traducción es una manera sesgada de leer críticamente el trabajo de otros y al mismo tiempo, un modo de intervención puesto que al ser traducido un texto se renueva (Benjamin, 79). Ello no implica un respeto absoluto por lo que se está trasladando a su lengua para permitir que la lengua extranjera "lo sacuda con violencia" (89). Por eso sostiene que el haber accedido a la lengua polaca lo llevó a "buscar uno de los rostros de Polonia y compartirlo con quien se adentre en la lectura de este libro. Es la faz que a mí me ha ofrecido. Un rostro compuesto de varios rostros" (Antología del cuento polaco 7).

La significación de su encuentro con el mundo literario polaco queda expresada también en El arte de la fuga cuando señala los distintos momentos e intensidades nacidos de su vinculación con la literatura: la lectura, la inmensa libertad para escribir y el aprovechamiento del tiempo generaban que viviera la literatura como un "acto de hedonismo puro" (14). Al mismo tiempo, la evocación de ese tiempo de lecturas, de redescubrimiento o de encuentro con otras voces literarias está asociado también con el período de escritura, cuestión que lo lleva a sostener que su relación con la literatura "ha sido visceral, excesiva y aun salvaje" (15),

12 Citado en (1989) Bajtin, M. Teoría y estética de la novela. Madrid, Taurus: 430.

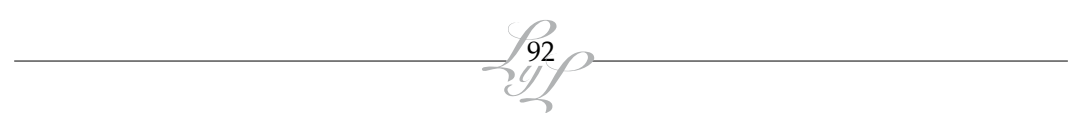


idea que mantiene a lo largo de toda su producción. En Una autobiografía soterrada reafirma el valor de la libertad para elegir la forma más adecuada para expresar ese desborde vital que debe ser la literatura:

Descreo de los decálogos y las recetas universales. La Forma que llega a crear un escritor es resultado de toda su vida: la infancia, toda clase de experiencias, los libros preferidos, la constante intuición. Sería monstruoso que todos los escritores obedecieran las reglas de un mismo decálogo o que siguieran el camino de un único maestro. Sería la parálisis, la putrefacción.

Esta libertad que reclama para la escritura está presente en las traducciones. En gran medida esta tarea permite cartografiar el corpus narrativo del mexicano ya que la mayoría de ellas nacen a partir de sus lecturas, de sus viajes a países cuyas lenguas y literaturas lo deslumbran y, fundamentalmente, porque "[l]a traducción es, sin duda, la mejor escuela de internalización de la estructura de los géneros y de la propia lengua" (de Stefano 33) o como sostiene Pitol, no hay "mejor enseñanza para estructurar una novela que la traducción" (Una autobiografía soterrada 52). Esta actividad la efectúa con el acompañamiento del trabajo crítico, tal como se observa en el realizado con la obra de Pilniak, en especial en la minuciosa lectura realizada bajo el título "Boris Pilniak" y que sirve de nota introductoria a Pedro, Su Majestad, Emperador (2002). La traducción es del mexicano y en la nota que precede a Un cuento sobre cómo se escriben los cuentos, Pedro, Su Majestad, Emperador y Caoba desarrolla reflexiones sobre el género novelístico. El análisis está sostenido por dos ideas rectoras. Por un lado consideraciones acerca del modo narrativo, esto es, las técnicas empleadas por Pilniak y que lo posicionan como un escritor vanguardista y por otro, el peso que adquieren las cuestiones políticas en el contexto de su obra. Se confirma que el ensayo es el género que permite que una obra entable una compleja red de relaciones con otras obras. ${ }^{13}$

Ensayo, prólogo o estudio preliminar, "Boris Pilniak" delinea el perfil de la obra del ruso enmarcada en un contexto que bordea lo político y

13 Así define María Corti al género: "il luogo dove un'opera entra in una complessa rete di relazioni con altre opere". Cfr. "I genere letterari in prospettiva semiologica" en Strumenti critici. Revista quadrimestrale di cultura letteraria 17-19, Anno VI, febbraio 1972 fascicolo I. Giulio Einaudi Editore, Torino: 1-18. 
señala las afinidades y las herencias dejadas por un escritor definido por Pitol como "genial" (5) y que se atrevió a postular "el concepto de vanguardia [...] más audaz, más salvaje que la experimentación elegante, tardíamente simbolista que caracterizaba a la mayor parte de la literatura de la emigración" (5-6). El recorrido que realiza por la literatura rusa es el resultado de una lectura que hace Pitol de la revolución, del papel del intelectual y de sus observaciones acerca de la relación de otros escritores rusos con Occidente; acompaña este trazado sus reflexiones acerca de aspectos estrictamente literarios.

El estilo y los "métodos de narración" (8) empleados por Pilniak son sometidos a un agudo análisis evidenciando la condición del mexicano de avezado crítico literario. Pitol lee una novela y centra sus observaciones en los aspectos vanguardistas desplegados por el ruso, destacando como novedad que "[t]odo tiende en el libro a la destrucción, a la dispersión, a la desintegración de cuanto hasta el día anterior parecía compacto $\mathrm{u}$ homogéneo" (9). La suma de distintas discursividades que se encuentran en el interior de Caoba es lo que la distancia del relato tradicional. En esto radica el valor de esta novela pero, al mismo tiempo, es lo que lo lleva a establecer asociaciones con su propia obra. Si lo que destaca como original está focalizado en "el uso de páginas de diarios eclesiásticos, bandos cívicos, pregones mercantiles, párrafos extraídos de libros teosóficos, páginas salidas de quién sabe dónde" (9), esta valoración reenvía a algunos libros de Pitol (El viaje 28-51).

El arte de la fuga, por caso, alberga referencias a su propia obra, lo que en gran medida guía al lector a encontrarse con el ars poética pitoliana, cuestión que, incluso, se fortalece con las habituales referencias autobiográficas. Éstas muestran no sólo su trayectoria de escritor sino también la de diplomático, periodista y traductor. Pitol construye su obra a partir de su temprana experiencia lectora, su condición de diplomático, de cronista y de escritor para, de inmediato, incluir episodios deudores del diario privado. El lector se enfrenta con el trazado de la vida literaria de un sujeto que se observa a sí mismo: "En vez de ensañarme contra mis limitaciones he aprendido a contemplarlas con condescendencia y aun con cierta complicidad. De ese juego nace mi escritura: al menos así me lo parece" (El viaje 9).

Subvierte particularidades de la ficción para teñirlas de reflexiones y así poder desplegar su idea de la escritura recurriendo a la inclusión de 
nombres de la literatura para dejar a la vista sus afinidades electivas. De este modo, Pitol logra violentar los límites genéricos impulsando al lector a rearmar campos y aproximarse o reencontrarse con distintas literaturas. Su obra muestra marcas de interlocución, guía a confrontar saberes y discute doctrinas. En términos de Glaudes son textos que se asocian con el concepto de "ensayo-debate" (op. cit.). La lectura y la escritura se reúnen para generar un espacio de reflexión en el que es posible comprender que "sin los otros no habría ensayo" (Cerutti Guldberg 1993). Cada uno de los ensayos pone en marcha un pensamiento que impulsa a la deliberación, a una marcha balbuceante, resultado del constante devenir reclamado por Michel de Montaigne, movimiento que conjuga con la ficción, lo que da como resultado una obra que se puede leer como un gran libro donde los 'dioses tutelares' impulsan la creación de imágenes siempre novedosas.

\section{Bibliografía}

Barthes, Roland (1987). El susurro del lenguaje. Más allá de la palabra y la escritura. Barcelona/Buenos Aires: Paidós.

Benjamin, Walter (2007). Conceptos de filosofía de la historia. Traducción de H. A. Murena y D. J. Vogelmann: Buenos Aires: Terramar Ediciones.

Cerutti Guldberg, Horacio (1993). "Hipótesis para una teoría del ensayo". En AA.VV., El ensayo en Nuestra América. Para una reconceptualización (Presentación de Horacio Cerutti Guldberg). México: UNAM, 13-26.

De Stefano, Victoria (2000). "Pitol, un proyecto de vida". En AA.VV. Sergio Pitol. Los territorios del viajero. México: Era, 33-40.

García Ponce, Juan (2001). Las huellas de la voz. Homenajes. México: Editorial Joaquín Mortiz/Editorial Planeta Mexicana.

Glaudes, Pierre. (2002). L'essai: Métamorphoses d'un genre. Toulouse: Presses Universitaires du Miral.

Obaldia, Claire de (1995). The essayistic spirit. Literatura, Modern Criticism, and the Essay, Oxford: Clarendon Press.

Pilniak, Boris (2002). Pedro, Su Majestad, Emperador. Traducción de Sergio Pitol. Santiago de Chile: LOM. 
Pitol, Sergio (2011). Una autobiografía soterrada. Barcelona: Anagrama. . (2006). La casa de la tribu. Vizcaya: Fondo de Cultura Económica - Universidad de Alcalá, Servicio de Publicaciones. . (2006). El mago de Viena. Bogotá: Fondo de Cultura Económica. . (2005). El arte de la fuga. Barcelona, Anagrama. . (2000). El viaje. Barcelona: Anagrama. . (2000). Todo está en todas las cosas. Santiago de Chile: LOM. . (1988). Domar a la divina garza. Barcelona: Anagrama. . (1967). Antología del cuento polaco contemporáneo. Prólogo y traducción de Sergio Pitol. México: Era.

Ricoeur, Paul (2009). Sobre la traducción. Traducción y prólogo de Patricia Wilson. Buenos Aires: Paidós.

Volpi, Jorge (2000). "Siete variaciones sobre temas originales de Sergio Pitol". En AA.VV. Sergio Pitol. Los territorios del viajero. México: Era, 103-113.

Weinberg, Liliana (Editora) (2003). Ensayo, simbolismo y campo cultural. México: UNAM. 